\title{
Relações solo-superfície geomórfica e evolução da paisagem em uma área do Planalto Central Brasileiro(1)
}

\author{
Paulo Emilio Ferreira da Motta(2), Amaury de Carvalho Filho(2), João Carlos $\operatorname{Ker}^{(3)}$, \\ Nilson Rendeiro Pereira(2), Waldir de Carvalho Junior ${ }^{(2)}$ e Philippe Blancaneaux ${ }^{(4)}$
}

\begin{abstract}
Resumo - Com base em levantamento pedológico de reconhecimento de alta intensidade, foram investigadas relações pedogeomorfológicas em uma área do Planalto Central Brasileiro, com vistas à predição de atributos e distribuição dos solos em áreas vizinhas carentes de mapas pedológicos. Três superfícies geomórficas, com distintos padrões de espacialização de solos, foram identificadas. Na mais elevada, a distribuição dos solos é estreitamente relacionada à variação do regime hídrico ao longo das encostas. Ocorrem Latossolo Vermelho (LV), Latossolo Vermelho-Amarelo (LVA), Latossolo Amarelo (LA), Latossolo Amarelo plíntico, Latossolo Amarelo petroplíntico (concrecionário) e Plintossolo Háplico, todos muito argilosos, com teores de $\mathrm{Fe}_{2} \mathrm{O}_{3}$ e $\mathrm{TiO}_{2}$ relativamente homogêneos e índices $\mathrm{Ki}$ e $\mathrm{Kr}$ indicativos de mineralogia oxídica. Na segunda superfície, os solos apresentam maior variação quanto à textura e teores de Fe e Ti. Predominam LV e LV acriférrico, além de LVA e LA. Nos limites com as chapadas, observa-se a ocorrência de LVA e LA acriférricos endopetroplínticos. Na terceira superfície, que disseca as anteriores, predominam solos menos intemperizados, com atributos muito variáveis, como Cambissolo Háplico, Argissolos Vermelho e Vermelho-Amarelo, Nitossolo Vermelho eutroférrico, Neossolo Litólico e Neossolo Flúvico. O trabalho inclui a proposição de um modelo de evolução para a paisagem regional.
\end{abstract}

Termos para indexação: cerrados, pedogênese, aspectos morfológicos do solo, geomorfologia.

\section{Soil-geomorphic surface relationships and landscape evolution in an area of the Brazilian Central Plateau}

\begin{abstract}
The soil-geomorphic surface relationships were investigated in an area of the Central Brazilian Plateau, based upon a high intensity reconnaissance pedological survey, aiming at the prevision of the soil attributes and their distribution in adjacent areas which don't have pedological maps. Three geomorphic surfaces, with distinctive soil distribution patterns, were identified. In the highest geomorphic surface, the soil distribution is highly related to the hydric regime variation along the hillsides, occurring Red Latosol (RL), Red-Yellow Latosol (RYL), Yellow Latosol (YL), Plinthic Yellow Latosol, Petroplinthic Yellow Latosol (PYL) (concretionary soil) and Haplic Plinthosol. These soils show very clayey texture, values of $\mathrm{Fe}_{2} \mathrm{O}_{3}$ and $\mathrm{TiO}_{2}$ relatively homogeneous, and $\mathrm{Ki}$ and $\mathrm{Kr}$ indexes indicatives of oxidic mineralogy. In the second surface, the soils show higher variation with respect to texture and iron and titanium contents. RL, Acricferric RL, RYL and YL are the dominant soils, with occurrence of Acriferric Endopetroplinthic RYL and YL near the borders of the high tablelands. In the third surface, that cuts the first and second ones, predominate less weathered soils, with high variable attributes, such as Haplic Cambisol, Red and Red-Yellow Argisols, Eutroferric Red Nitosol, Litholic Neosol and Fluvic Neosol. This work includes a proposition of a regional landscape evolution model.
\end{abstract}

Index terms: savannas, soil genesis, soil morphological features, geomorphology.

(1) Aceito para publicação em 17 de agosto de 2001.

(2) Embrapa-Centro Nacional de Pesquisa de Solos, Rua Jardim Botânico, 1024, CEP 22460-000 Rio de Janeiro, RJ. E-mail: motta@cnps.embrapa.br, amaury@cnps.embrapa.br, nilson@cnps.embrapa.br, waldir@cnps.embrapa.br

(3) Universidade Federal de Viçosa, Dep. de Solos, CEP 36570-000 Viçosa, MG. E-mail: jcker@solos.ufv.br

(4) Institut de Recherche pour le Développement, 32 Avenue Henri Varagnat, 93143 Bondy cedex, França. E-mail: Philippe.Blancaneaux@bondy.ird.fr

\section{Introdução}

As informações a respeito da distribuição de solos na região dos cerrados, fundamentadas principalmente em levantamentos de solos generalizados, já que poucos foram os trabalhos realizados em nível de detalhe ou semidetalhe na região, permitem concluir que, não obstante a monotonia da paisagem, os solos dos cerrados são bastante variáveis. Apesar 
de serem lembrados freqüentemente como profundos, pobres em nutrientes, praticamente sem minerais primários facilmente intemperizáveis e localizados em áreas planas a suave onduladas, ocorrem também solos rasos, principalmente Cambissolos e Neossolos Litólicos, situados em áreas acidentadas e que, embora comumente álicos, podem ser inclusive eutróficos (Resende et al., 1988). Nas áreas de relevo mais movimentado podem ser também encontrados outros solos eutróficos (Argissolos e Nitossolos) geralmente relacionados com a proximidade de um material de origem mais rico (Ker \& Resende, 1996).

O conhecimento das relações entre solo e superfície geomórfica, aqui considerada como uma porção da paisagem especificamente definida no espaço e no tempo, conforme Ruhe (1969), pode subsidiar levantamentos de solos (Rodrigues \& Klamt,1978), constituindo poderoso instrumento de predição da feição pedológica de áreas ainda não conhecidas, ao permitir a identificação da toposseqüência típica e o entendimento da distribuição espacial e das características dos solos de uma região. Além disso, possibilita a extrapolação de informações disponíveis em mapas de solos em qualquer escala, para locais e objetivos mais específicos, implicando a redução de tempo e de custos para obtenção de dados ambientais básicos.

Estudos mais generalizados sobre relações solo-paisagem na região do Planalto Central Brasileiro foram realizados por Feuer (1956), enquanto trabalhos mais detalhados e em locais específicos foram desenvolvidos por Cavalcante (1977), Mothci (1977), Rodrigues \& Klamt (1978) e Carmo et al. (1984) na região dos cerrados.

O objetivo deste trabalho foi identificar as principais relações solo-superfícies geomórficas prevalecentes em uma área representativa de grande parte do Planalto Central Brasileiro, para aprofundar a compreensão sobre a gênese dos solos da região e subsidiar a extrapolação de informações de um mapa de solos de reconhecimento para áreas vizinhas.

\section{Material e Métodos}

Durante o levantamento de reconhecimento de alta intensidade dos solos dos Municípios de Silvânia e
São Miguel do Passa-Quatro (Embrapa, 1992), que abrangem uma área de $3.620 \mathrm{~km}^{2}$ no Estado de Goiás, foram investigadas as relações entre solos e superfícies geomórficas, cuja distinção e estimativa de idades relativas foram realizadas com base nos conceitos de Daniels et al. (1971). Os limites destas unidades foram verificados no campo, com o apoio de fotografias aéreas 1:60.000 (vôo AST-10 da USAF, 1965), imagens de satélite (TM-LANDSAT-5, canais 2, 3 e 4) 1:100.000 e cartas planialtimétricas 1:100.000, do SGE.

Os solos foram identificados e caracterizados por meio de tradagens, observações de barrancos e trincheiras, com descrição de perfis e coleta de amostras em locais representativos, conforme Lemos \& Santos (1996) e Reunião... (1979). As amostras foram analisadas nos laboratórios da Embrapa-Centro Nacional de Pesquisa de Solos, de acordo com os métodos constantes em Embrapa (1979). Após separação e quantificação volumétrica de calhaus e cascalhos, foram determinadas na TFSA: granulometria, argila dispersa em água, $\mathrm{pH}$ em água e em $\mathrm{KCl} 1 \mathrm{~N}, \mathrm{P}$ disponível, cátions trocáveis $\left(\mathrm{Ca}^{2+}, \mathrm{Mg}^{2+}, \mathrm{K}^{+}, \mathrm{Na}^{+}\right), \mathrm{Al}^{3+} \mathrm{e}$ acidez $\left(\mathrm{H}^{+}\right.$ $+\mathrm{Al}^{3+}$ ) extraíveis, carbono orgânico, $\mathrm{N}$ total e teor de óxidos $\left(\mathrm{SiO}_{2}, \mathrm{Al}_{2} \mathrm{O}_{3}, \mathrm{Fe}_{2} \mathrm{O}_{3}\right.$ e $\left.\mathrm{TiO}_{2}\right)$ pelo ataque sulfúrico.

Numa segunda fase, contando também com o apoio de mapas geológicos (Brasil, 1975, 1983; Valente \& Veneziani, 1988) e geomorfológico (Brasil, 1983), a área foi novamente percorrida, de forma abrangente, com o objetivo de complementar as observações e verificar as inter-relações entre os diferentes componentes do meio físico.

A classificação dos solos encontra-se de acordo com o sistema brasileiro de classificação de solos (Embrapa, 1999).

\section{Resultados e Discussão}

\section{Descrição geral da área}

A área estudada compreende os Municípios de Silvânia e São Miguel do Passa-Quatro, GO, situados a leste de Goiânia e ao sul do Distrito Federal, entre $16^{\circ} 16^{\prime}$ e $17^{\circ} 10^{\prime}$ de latitude Sul e $48^{\circ} 10^{\prime}$ e $48^{\circ} 55^{\prime}$ de longitude Oeste. Inserida na unidade geomorfológica "Planalto do Alto Tocantins-Paranaíba", subdivisão do "Planalto Central Goiano" (Brasil, 1983), constitui exemplo clássico de evolução policíclica de paisagem, que inclui, ao lado de formas mais jovens, remanescentes bem preservados de superfícies antigas (Lepsch \& Buol, 1988). Distinguem-se aí três superfícies geomórficas (Figura 1), inicialmente identificadas por Feuer (1956) na área do Distrito Federal e por ele denominadas "primeira, segunda e terceira superfícies". 
A primeira superfície (superfície I) corresponde ao antigo peneplano elaborado pelo ciclo de erosão "Sul-Americano" (Braun, 1971), considerado por King (1956) o elemento fundamental do cenário geomorfológico brasileiro, cujos remanescentes constituem as chapadas atuais, com declives inferiores a 3\%. Seus topos, esculpidos em espessa cobertura de sedimentos terciários (Brasil, 1983), elevam-se entre 1.000 e $1.100 \mathrm{~m}$ de altitude, e as bordas, salientes, são recobertas em quase toda a extensão por espessa camada de canga laterítica.

A segunda superfície (superfície II) se estende na forma de plano inclinado a partir das bordas da primeira em direção aos cursos d'água principais. Corresponde a um pediplano pleistocênico (Braun, 1971) de conformação suave, originado pela dissecação da superfície I pelo ciclo de erosão "Velhas"(King, 1956).

A terceira superfície (superfície III), caracterizada por uma topografia mais acidentada que as anteriores, com predominância de relevos ondulado e forte ondulado, corresponde às áreas de dissecação mais recente.
A litologia da área é representada por gnaisses e migmatitos do Complexo Goiano, micaxistos e quartzitos do Grupo Araxá, filitos e quartzitos do Grupo Canastra e metassiltitos e metargilitos da Formação Paraopeba, Grupo Bambuí (Brasil, 1983). Destacam-se, dentro do Complexo Goiano, um conjunto de rochas básicas que Valente \& Veneziani (1988) denominaram "Complexo Granulítico Anápolis-Itauçu” (CGAI). Na primeira superfície e em algumas áreas da segunda, essas rochas encontram-se recobertas por sedimentos terciários e quaternários, respectivamente (Brasil, 1983). Áreas aluvionares holocênicas apresentam pequena expressão geográfica.

\section{Relações solo-superfícies geomórficas}

Primeira superfície

A distribuição dos solos nesta superfície difere em função da extensão das chapadas, assemelhando-se, em parte, nos remanescentes mais largos, à descrita por Rodrigues \& Klamt (1978) e Macedo \& Bryant (1987) para áreas do DF. Do centro

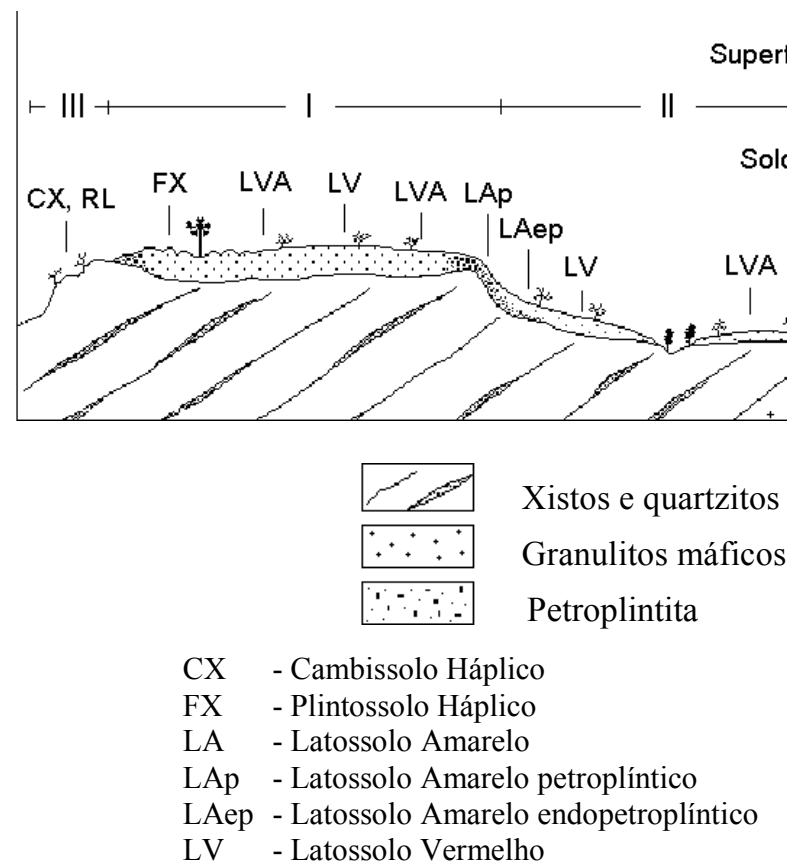

uperficies

Solos 
para as bordas, ocorrem seqüencialmente: Latossolo Vermelho (LV), Latossolo Vermelho-Amarelo (LVA) ou Latossolo Amarelo típico (LA), Latossolo Amarelo plíntico e Latossolo Amarelo petroplíntico (LAp) (concrecionário), este constituindo a maior parte dos limites com a segunda superfície. Solos hidromórficos ocorrem nas áreas de surgência de água (Figura 1). Nas chapadas mais estreitas não se observa a ocorrência de LV e os solos concrecionários sobressaem, chegando inclusive a dominar a chapada.

Desenvolvidos a partir de um sedimento fino, sem evidências de relação direta com as litologias subjacentes (Brasil, 1962; Braun, 1971; Bennema et al., 1962, citados por Queiroz Neto, 1982), como indica a grande homogeneidade granulométrica dos perfis, com amplo domínio da fração argila (Tabela 1), independentemente da natureza do substrato rochoso, os solos dessa superfície mostram uma distribuição condicionada sobretudo pela variação do regime hídrico ao longo das vertentes suaves. A ocorrência de LV em local mais elevado, no centro das chapadas, está relacionada a condições de melhor drenagem interna, como evidenciam suas cores de matiz tão ou mais vermelho que 2,5YR, indicativas da presença de hematita na fração argila, óxido de ferro típico de ambientes oxidantes (Schwertmann, 1988). Por sua vez, a ocorrência de LVA e LA em contorno ao LV está relacionada a um pedoambiente mais úmido, devido à proximidade com o material concrecionário das bordas das chapadas ou com as zonas de surgência, favorável, como observado por Macedo \& Bryant (1987), à formação preferencial da goethita sobre a hematita, ou à sua maior persistência no sistema.

Solos hidromórficos estão associados às áreas ligeiramente deprimidas, no interior ou próximo às bordas das chapadas, onde se localizam as nascentes da escassa rede de drenagem dessa superfície.

Tabela 1. Características físicas, químicas e cor úmida de horizontes selecionados de solos do Planalto Central Brasileiro situados na primeira superfície geomórfica(1).

\begin{tabular}{|c|c|c|c|c|c|c|c|c|c|c|c|c|c|c|c|}
\hline \multirow[t]{2}{*}{ Horizonte } & \multirow{2}{*}{$\begin{array}{l}\text { Profundidade } \\
\text { (cm) }\end{array}$} & \multirow{2}{*}{$\begin{array}{l}\text { Cor } \\
\text { (úmida) }\end{array}$} & \multirow{2}{*}{$\mathrm{s}$} & \multirow[t]{2}{*}{$\mathrm{r}$} & \multirow{2}{*}{$\begin{array}{l}\mathrm{C} \\
\text { org. }\end{array}$} & \multicolumn{2}{|c|}{$\mathrm{pH}$} & \multirow[b]{2}{*}{-----. } & \multirow[t]{2}{*}{$\mathrm{T}$} & \multirow[t]{2}{*}{$\mathrm{V}$} & \multirow{2}{*}{$\mathrm{m}$} & \multirow{2}{*}{\multicolumn{2}{|c|}{$\begin{array}{l}\mathrm{Fe}_{2} \mathrm{O}_{3} \quad \mathrm{TiO}_{2} \\
----\left(\mathrm{g} \mathrm{kg}^{-1}\right)---- \\
\end{array}$}} & \multirow[t]{2}{*}{$\mathrm{Ki}$} & \multirow[t]{2}{*}{$\mathrm{Kr}$} \\
\hline & & & & & & $\mathrm{H}_{2} \mathrm{O}$ & $\mathrm{KCl}$ & & & & & & & & \\
\hline & & & \multicolumn{9}{|c|}{$\begin{array}{c}\text { Latossolo Vermelho ácrico } \\
\text { Perfil TS-17 }\end{array}$} & & & & \\
\hline Ap & $0-17$ & 2,5 YR $3 / 5$ & 100 & 690 & 19,5 & 4,7 & 4,6 & 2,1 & 9,3 & 23 & 13 & 130 & 9,5 & 0,72 & 0,54 \\
\hline Bw2 & $106-150$ & 2,5 YR $4 / 6$ & 100 & 730 & 5,8 & 4,9 & 6,0 & 0,4 & 2,2 & 18 & 0 & 133 & 11,2 & 0,72 & 0,55 \\
\hline \multicolumn{16}{|c|}{$\begin{array}{l}\text { Latossolo Vermelho-Amarelo distrófico } \\
\text { Perfil SIL-37 }\end{array}$} \\
\hline A & $0-20$ & $5 Y R 4 / 4$ & 150 & 790 & 19,2 & 4,5 & 3,8 & 0,6 & 8,0 & 8 & 57 & 64 & 12,0 & 1,15 & 0,99 \\
\hline Bw & $70-100$ & 5YR 5/8 & 90 & 830 & 8,0 & 4,9 & 4,3 & 0,6 & 4,7 & 13 & 14 & 69 & 13,0 & 1,07 & 0,93 \\
\hline \multicolumn{16}{|c|}{ Perfil SIL-28 } \\
\hline A & $0-18$ & $5 Y R 4 / 4$ & 110 & 820 & 15,2 & 4,7 & 3,9 & 1,0 & 12,4 & 8 & 47 & 96 & 12,0 & 0,60 & 0,51 \\
\hline Bw & $70-100$ & 5 YR $5 / 8$ & 100 & 790 & 11,4 & 5,0 & 4,7 & 0,9 & 6,6 & 14 & 10 & 103 & 12,6 & 0,61 & 0,51 \\
\hline \multicolumn{16}{|c|}{$\begin{array}{c}\text { Latossolo Vermelho-Amarelo ácrico } \\
\text { Perfil TS-23 }\end{array}$} \\
\hline A & $0-17$ & $5 Y R 3 / 3$ & 130 & 750 & 22,7 & 4,5 & 4,4 & 0,5 & 9,2 & 5 & 71 & 114 & 10,8 & 0,53 & 0,43 \\
\hline Bw2 & $93-170$ & $5 Y R 4 / 8$ & 80 & 820 & 9,2 & 5,3 & 5,8 & 0,3 & 3,4 & 9 & 0 & 120 & 13,3 & 0,54 & 4,01 \\
\hline \multicolumn{16}{|c|}{$\begin{array}{l}\text { Latossolo Amarelo ácrico } \\
\text { Perfil TS-4 }\end{array}$} \\
\hline Ap & $0-19$ & $10 \mathrm{YR} 4 / 3$ & 150 & 660 & 17,5 & 5,2 & 4,1 & 4,0 & 7,8 & 51 & 0 & 122 & 14,3 & 0,62 & 0,48 \\
\hline Bw1 & $80-119$ & 7,5YR 5/6 & 80 & 780 & 8,8 & 6,0 & 5,9 & 0,4 & 3,6 & 11 & 0 & 124 & 17,4 & 0,57 & 0,45 \\
\hline Bwcf & $155-189^{+}$ & 7,5YR 5/6 & 100 & 770 & 5,7 & 4,7 & 4,6 & 0,4 & 2,2 & 18 & 0 & 119 & 17,5 & 0,67 & 0,53 \\
\hline \multicolumn{16}{|c|}{$\begin{array}{c}\text { Latossolo Amarelo ácrico petroplíntico } \\
\text { Perfil TS-2 }\end{array}$} \\
\hline Acf & $0-25$ & 7,5YR 4/2 & 70 & 310 & 13,7 & 4,6 & 4,1 & 0,6 & 7,2 & 8 & 67 & 156 & 10,6 & 0,71 & 0,42 \\
\hline Bwcf1 & $78-135$ & 7,5YR 5/6 & 90 & 620 & 8,0 & 4,7 & 4,6 & 0,4 & 4,0 & 10 & 33 & 156 & 11,0 & 0,71 & 0,50 \\
\hline Bwcf2 & $135-220$ & 7,5YR 5/8 & 120 & 610 & 4,8 & 4,1 & 5,6 & 0,3 & 2,3 & 13 & 0 & 174 & 11,0 & 0,73 & 0,49 \\
\hline \multicolumn{16}{|c|}{$\begin{array}{l}\text { Plintossolo Háplico distrófico } \\
\text { Perfil TS-18 }\end{array}$} \\
\hline $\mathrm{AB}$ & $5-17$ & 10 YR $7 / 2$ & 130 & 700 & 19,0 & 5,2 & 5,4 & 0,5 & 4,8 & 10 & 0 & 54 & 13,3 & 0,31 & 0,28 \\
\hline $\mathrm{Bf}$ & $17-38$ & $2,5 Y 7 / 4$ & 150 & 720 & 9,7 & 5,4 & 6,6 & 0,5 & 2,4 & 21 & 0 & 107 & 14,9 & 0,35 & 0,29 \\
\hline Bgf2 & $75-120$ & $2,5 Y 7 / 4$ & 160 & 690 & 3,4 & 6,1 & 7,3 & 0,3 & 0,9 & 33 & 0 & 118 & 15,3 & 0,40 & 0,33 \\
\hline
\end{tabular}

${ }^{(1)}$ s: silte; r: argila; $\mathrm{S}$ : soma de bases; T: capacidade de troca de cátions; V: saturação por bases; m: saturação por Al. ${ }^{(2)}$ Corresponde ao número de campo constante em Embrapa (1992). 
Estas áreas são caracterizadas por um relevo singular constituído por grande quantidade de murundus (microelevações com 1 a 1,5 $\mathrm{m}$ de altura e 5 a $10 \mathrm{~m}$ de diâmetro, em média), considerados por Corrêa (1989) como de origem biológica, entremeados por sulcos de fundo plano, onde, em grande parte do ano, aflora água. Esse conjunto, regionalmente denominado covoal, tem sido constatado em diversas regiões do Brasil Central (Embrapa, 1982; Corrêa, 1989; Motta \& Kämpf, 1992; Resende et al., 1999). A alternância de redução e oxidação, condicionada pela oscilação do lençol freático, induziu nessas áreas a formação de plintita em subsuperfície. Predomina aí Plintossolo Háplico, ocorrendo em menor proporção LA plínticos, ambos sob campo higrófilo, que se diferencia da vegetação arbórea de cerrado que originalmente recobria os demais solos das chapadas. Gleissolos ocorrem nas veredas, pequenos cursos d'água aos quais está associada a palmeira buriti (Mauritia vinifera).
Os limites dessa superfície são representados por bordas salientes, cujos solos apresentam grande quantidade de calhaus, cascalhos e matacões de petroplintita entremeados de material latossólico. Apesar de englobarem grandes variações em suas características, inclusive, algumas vezes, gradiente textural, estes solos foram classificados em conjunto como LAp, e correspondem aos solos denominados Latossolos Petroplínticos em Embrapa (1983). Em geral ocupam posição ligeiramente mais elevada em relação ao nível das chapadas, o que indica um rebaixamento da superfície original do peneplano devido à menor resistência oferecida pelos demais solos à erosão geológica.

\section{Segunda superfície}

Evidenciando maior influência do substrato rochoso, os solos da segunda superfície apresentam características mais variáveis, como indicado pelos teores de $\mathrm{Fe}_{2} \mathrm{O}_{3}$ e $\mathrm{TiO}_{2}$ (Tabela 2). Predominam LV,

Tabela 2. Características físicas, químicas e cor úmida de horizontes selecionados de solos do Planalto Central Brasileiro situados na segunda superfície geomórfica ${ }^{(1)}$.

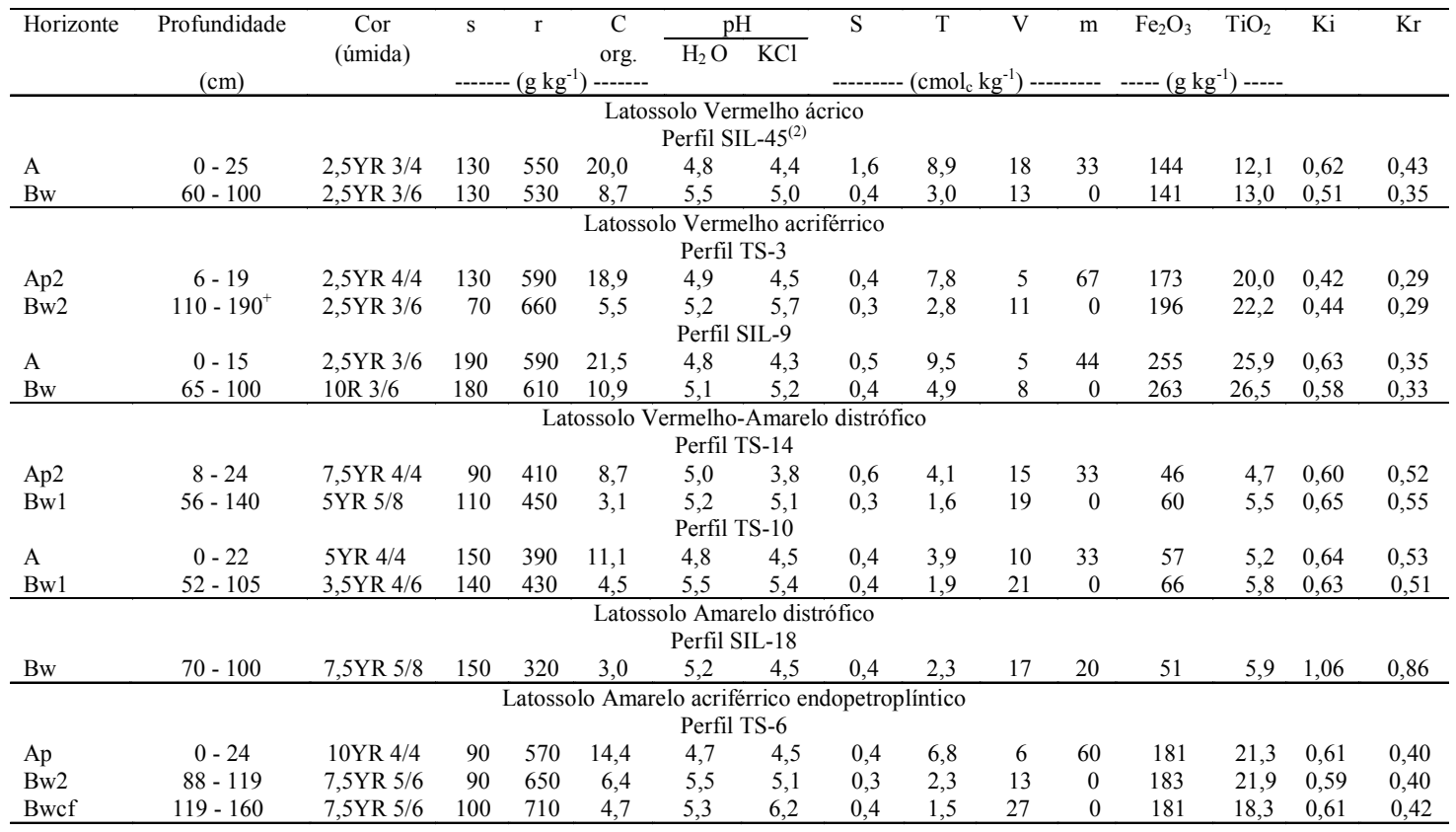

${ }^{(1)}$ s: silte; r: argila; S: soma de bases; T: capacidade de troca de cátions; V: saturação por bases; m: saturação por Al. ${ }^{(2)}$ Corresponde ao número de campo constante em Embrapa (1992). 
LVA e LA, com ocorrência mais restrita de LV acriférrico (antigo Latossolo Roxo), relacionada a granulitos máficos do Complexo Granulítico Anápolis-Itauçu, e também registrada por Cline \& Buol (1973) e Motchi (1977). Na base da encosta que a separa da primeira superfície é comum a ocorrência de Latossolos de cor vermelho-amarelada ou amarelada (LVA ou LA), em cujos perfis ocorrem leitos de concreções lateríticas individualizadas e arredondadas, que definem o caráter endopetroplíntico, como exemplifica o perfil TS-6 (Tabela 2). A disposição destas concreções na forma de linha de pedras, sua ocorrência em faixa não muito extensa a partir das bordas da primeira superfície, a mistura com material latossólico e o pequeno tamanho, contrastando-se com as da superfície mais elevada, onde chegam a constituir grandes blocos justapostos, sugere tratar-se de depósitos de material proveniente das áreas mais altas.

A partir da mistura do material pré-intemperizado, oriundo da primeira superfície, com material menos alterado proveniente da decomposição das rochas subjacentes, desenvolveram-se, portanto, os solos da segunda superfície, cuja distribuição e características dependem da maior ou menor contribuição de cada um deles. Dessa forma, solos de textura argilosa predominam onde essa superfície corta xistos pré-cambrianos (Grupo Araxá), muito argilosos quando a rocha subjacente é o granulito máfico ou é grande a contribuição de sedimentos terciários da primeira superfície, e de textura média quando a rocha subjacente é o quartzito (Grupo Araxá). Como os solos da primeira superfície, são também distróficos, às vezes epiálicos. Os baixos valores de Ki indicam uma mineralogia predominantemente oxídica e a freqüente superioridade dos valores de $\mathrm{pH}$ em $\mathrm{KCl}$ em relação aos de pH em água (Tabela 2), caracteriza-os como eletropositivos.

Apesar da diferença entre os períodos de tempo em que os materiais originários dos solos da primeira e segunda superfícies estiveram expostos ao intemperismo, os valores de Ki não mostram diferenças significativas quanto ao grau de desenvolvimento pedogenético (Tabelas 1 e 2), o que concorda com observações de Cline \& Buol (1973). Há, inclusive, uma tendência de serem estes índices mais baixos nos solos da segunda superfície, o que pode ser atribuído à contribuição do material pré-intemperizado da primeira superfície ou a um intemperismo mais intenso, permitido pelas condições mais livres de drenagem nessas áreas. Estudos mais específicos são no entanto necessários para o melhor esclarecimento desse fato.

A vegetação dominante na segunda superfície é também o cerrado, com áreas restritas de cerradão e floresta subcaducifólios, sendo o relevo dominantemente suave ondulado, com menores extensões de áreas planas. Esta superfície está sendo dissecada pelos processos erosivos atuais, como evidencia a ocorrência, principalmente no centro-norte da área estudada, de pequenos remanescentes dela, que ali subsistem, contornados por áreas da terceira superfície. Na zona de contato entre elas a susceptibilidade à erosão é significativamente mais elevada, e o ravinamento, quando acelerado pela retirada da vegetação para instalação de projetos agropecuários ou de mineração, dá origem a grandes voçorocas.

\section{Terceira superfície}

Nesta superfície distinguem-se dois compartimentos: um, erosional, de relevo bastante movimentado, onde a relação entre os solos e o substrato rochoso é estreita, que corresponde aos locais onde a erosão geológica promoveu o desgaste das superfícies mais antigas e retrabalha atualmente o substrato rochoso, e uma pequena zona deposicional, correspondente às planícies fluviais. No primeiro caso, predominam solos rasos, principalmente Cambissolo Háplico (CX), e, em menores proporções, Argissolo Vermelho (PE), Argissolo Vermelho-Amarelo (PV) e Nitossolo Vermelho eutroférrico (NVef) (antiga Terra Roxa Estruturada), este último associado a afloramentos de rochas do Complexo Granulítico Anápolis-Itauçu, no oeste da área, além de Neossolo Litólico (RL). O relevo varia de suave ondulado a montanhoso, e a vegetação acompanha a grande variabilidade dos solos, com ocorrência de floresta, cerradão e cerrado, além de campo cerrado e campos tropicais. Nas áreas ocupadas por NVef, PE e PV, a vegetação é sempre floresta, relacionada à maior fertilidade natural desses solos. Matas de galeria ocorrem nas planícies fluviais, sobre Neossolo Flúvico nos vales mais amplos, ou sobre Gleissolos ao longo dos cursos d'água de menor expressão. 
Dada a forte relação entre atributos pedológicos e geológicos, os solos dessa superfície apresentam características bem mais variáveis. Ocorrem solos álicos, distróficos e eutróficos, com teores de Fe e Ti bastante distintos, e textura desde média até muito argilosa. Há, todavia, tendência dos solos com horizonte $\mathrm{B}$ textural ou B nítico apresentarem conteúdos de argila mais altos, acima de $45 \%$, e elevadas soma e saturação por bases (Tabela 3). O CX e o RL, ao contrário, caracterizam-se quase sempre pela baixa fertilidade natural, apresentando elevada saturação por alumínio. A ocorrência de calhaus e cascalhos, constituindo fase pedregosa, é também muito comum nesses solos; são raros os Cambissolos que não apresentam, pelo menos, cascalhos.

Ao contrário das superfícies mais velhas, não ocorre o caráter eletropositivo, e os valores de $\mathrm{Ki}$, embora característicos de argilas de baixa atividade, são em geral mais elevados.

\section{Modelo de evolução da paisagem}

A gênese de toda a região está relacionada à extensa superfície aplainada (Figura 2 I) referente ao ciclo de erosão Sul-Americano (King, 1956), elaborada, segundo o modelo de Suguio \& Bigarella (1979), em ambiente de extrema aridez, que perdurou por tempo suficientemente longo para moldar quase toda a paisagem brasileira. Condições climáticas mais úmidas que se seguiram propiciaram o aprofundamento do manto de intemperismo, e, num processo semelhante ao atual, ciclos alternados de oxidação e redução devem ter determinado, em áreas deprimidas, a segregação de ferro e formação de plintita em subsuperfície, precursora das concreções ferruginosas que agora persistem à borda das chapadas (Figura 2 I e II).

Completado o aplainamento Sul-Americano, o rebaixamento do nível de base de erosão pelos soerguimentos do Terciário Médio desencadeou a

Tabela 3. Características físicas, químicas e cor úmida de horizontes selecionados de solos do Planalto Central Brasileiro situados na terceira superfície geomórfica ${ }^{(1)}$.

\begin{tabular}{|c|c|c|c|c|c|c|c|c|c|c|c|c|c|c|c|}
\hline \multirow[t]{2}{*}{ Horizonte } & \multirow{2}{*}{$\begin{array}{l}\text { Profundidade } \\
\quad(\mathrm{cm})\end{array}$} & \multirow{2}{*}{$\begin{array}{l}\text { Cor } \\
\text { (úmida) }\end{array}$} & \multirow{2}{*}{$\mathrm{s}$} & \multirow[t]{2}{*}{$\mathrm{r}$} & $\mathrm{C}$ & \multicolumn{2}{|c|}{$\mathrm{pH}$} & \multirow[t]{2}{*}{$\mathrm{S}$} & \multirow[t]{2}{*}{$\mathrm{T}$} & \multirow[t]{2}{*}{$\mathrm{V}$} & \multirow[t]{2}{*}{$\mathrm{m}$} & \multirow{2}{*}{$\mathrm{Fe}_{2} \mathrm{O}_{3}$} & \multirow[t]{2}{*}{$\mathrm{TiO}_{2}$} & \multirow[t]{2}{*}{$\mathrm{Ki}$} & \multirow[t]{2}{*}{$\mathrm{Kr}$} \\
\hline & & & & & org. & \multicolumn{2}{|c|}{$\mathrm{H}_{2} \mathrm{O} \quad \mathrm{KCl}$} & & & & & & & & \\
\hline \multicolumn{16}{|c|}{$\begin{array}{l}\text { Nitossolo Vermelho eutroférrico } \\
\text { Perfil SIL- } 41^{(2)}\end{array}$} \\
\hline Ap & $0-25$ & $5 Y R 3 / 2$ & 250 & 480 & 19,8 & 5,8 & 5,0 & 18,2 & 25,5 & 71 & 0 & 160 & 37,0 & 1,64 & 0,99 \\
\hline $\mathrm{Bt}$ & $37-90$ & $2,5 \mathrm{YR} 3 / 6$ & 190 & 600 & 15,0 & 6,1 & 5,5 & 14,2 & 17,6 & 81 & 0 & 157 & 27,0 & 1,53 & 1,02 \\
\hline \multicolumn{16}{|c|}{ Argissolo Vermelho-Amarelo eutrófico } \\
\hline \multicolumn{16}{|c|}{ Perfil SIL-2 } \\
\hline A & $0-15$ & 10YR $3 / 4$ & 450 & 370 & 15,6 & 5,8 & 4,6 & 6,1 & 10,7 & 57 & 0 & 65 & 7,0 & 1,94 & 1,51 \\
\hline $\mathrm{Bt}$ & $50-70$ & 5YR 5/6 & 340 & 530 & 4,9 & 5,8 & 4,9 & 4,2 & 6,6 & 64 & 0 & 95 & 7,0 & 1,78 & 1,36 \\
\hline \multirow{2}{*}{\multicolumn{16}{|c|}{$\begin{array}{c}\text { Cambissolo Háplico Tb distrófico } \\
\text { Perfil TS-22 }\end{array}$}} \\
\hline & & & & & & & & & & & & & & & \\
\hline A & $0-10$ & 10YR $3 / 3$ & 250 & 340 & 15,9 & 4,6 & 3,9 & 1,8 & 7,8 & 23 & 63 & 55 & 4,2 & 2,13 & 1,54 \\
\hline $\mathrm{Bi}$ & $35-65$ & 7,5YR 6/6 & 270 & 440 & 5,6 & 4,7 & 4,0 & 0,6 & 5,2 & 12 & 84 & 72 & 4,0 & 2,01 & 1,51 \\
\hline \multicolumn{16}{|c|}{ Perfil TS-13 } \\
\hline A & $0-6$ & 7,5YR 4/4 & 250 & 220 & 11,7 & 5,3 & 4,4 & 1,2 & 4,1 & 29 & 25 & 34 & 3,3 & 1,34 & 1,10 \\
\hline $2 \mathrm{Bi} 2$ & $47-74$ & 5YR 5/6 & 350 & 330 & 3,0 & 5,5 & 4,2 & 0,5 & 2,2 & 23 & 17 & 53 & 5,4 & 1,17 & 0,96 \\
\hline \multirow{2}{*}{\multicolumn{16}{|c|}{$\begin{array}{c}\text { Cambissolo Háplico Tb eutrófico } \\
\text { Perfil SIL-16 }\end{array}$}} \\
\hline & & & & & & & & & & & & & & & \\
\hline A & $0-12$ & 10YR $3 / 2$ & 350 & 210 & 38,6 & 5,6 & 5,2 & 13,3 & 19,5 & 68 & 0 & 83 & 11,1 & 2,02 & 1,59 \\
\hline $\mathrm{Bi}$ & $31-55$ & 5YR 5/6 & 360 & 160 & 3,0 & 5,7 & 4,8 & 2,2 & 3,9 & 56 & 0 & 94 & 11,6 & 1,86 & 1,62 \\
\hline \multicolumn{16}{|c|}{$\begin{array}{c}\text { Neossolo Litólico distrófico } \\
\text { Perfil TS-25 }\end{array}$} \\
\hline A & $0-20$ & 10YR 4/4 & 360 & 420 & 15,0 & 4,6 & 3,9 & 1,0 & 7,3 & 14 & 75 & 75 & 12,0 & 2,04 & 1,46 \\
\hline \multirow{2}{*}{\multicolumn{16}{|c|}{$\begin{array}{l}\text { Neossolo Flúvico Tb distrófico } \\
\text { Perfil SIL-43 }\end{array}$}} \\
\hline & & & & & & & & & & & & & & & \\
\hline A & $0-20$ & 10YR $3 / 2,5$ & 410 & 450 & 29,9 & 4,9 & 4,2 & 4,8 & 14,9 & 32 & 25 & 58 & 6,4 & 1,68 & 1,42 \\
\hline $\mathrm{C} 3$ & $70-120$ & variegado & 220 & 260 & 2,9 & 5,5 & 4,1 & 1,1 & 3,6 & 31 & 48 & 38 & 4,5 & 1,73 & 1,42 \\
\hline \multicolumn{16}{|c|}{$\begin{array}{c}\text { Neossolo Flúvico Tb eutrófico } \\
\text { Perfil SIL-44 }\end{array}$} \\
\hline A & $0-20$ & $10 \mathrm{YR} 4 / 2$ & 620 & 250 & 14,5 & 4,9 & 4,5 & 5,2 & 6,8 & 76 & 19 & 37 & 3,7 & 1,86 & 1,59 \\
\hline $\mathrm{C} 2$ & $40-60$ & $10 \mathrm{YR} 4 / 2$ & 390 & 140 & 5,7 & 5,5 & 4,8 & 3,0 & 4,9 & 61 & 0 & 21 & 2,5 & 1,90 & 1,64 \\
\hline
\end{tabular}

${ }^{(1)}$ s: silte; r: argila; S: soma de bases; T: capacidade de troca de cátions; V: saturação por bases; m: saturação por $\mathrm{Al} .{ }^{(2)}$ Corresponde ao número de campo constante em Embrapa (1992) 
dissecação da paisagem, com a abertura de vales (Figura 2 III). Antes, porém, que toda a paisagem fosse dissecada, outro período seco se instalou, reduzindo, conseqüentemente, a vegetação. Grandes volumes de material desagregado deslocaram-se das encostas desprotegidas, atingidas por chuvas concentradas, depositando-se nas depressões. Dessa forma, ocorreu o entupimento dos vales, originando outra superfície de conformação suave (Figura 2 IV). Nessa fase, a maior parte do material plíntico deveria encontrar-se agregado em corpos vesiculares de grandes proporções nas bordas da primeira superfí-
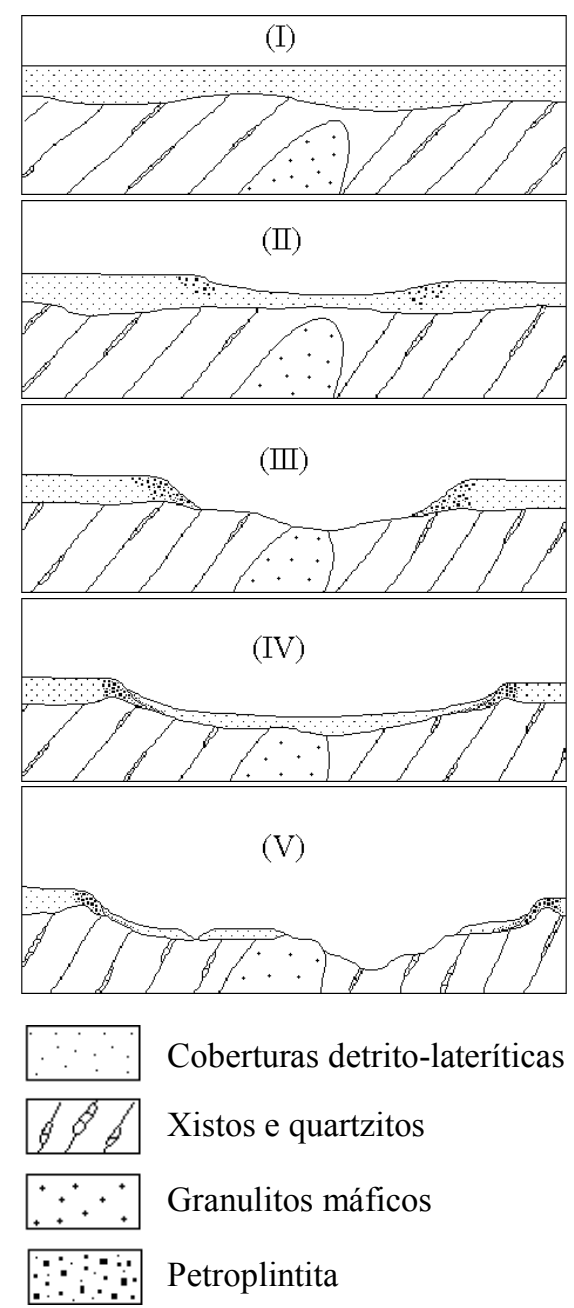

Figura 2. Modelo proposto da evolução da paisagem em área do Planalto Central Brasileiro. cie de erosão, mas apenas uma pequena parte, já individualizada, ou que veio a ser desagregada pelo intemperismo subseqüente, foi depositada nos vales. A crosta de material petroplíntico das bordas, resistindo ao processo erosivo natural, contribuiu para a manutenção das chapadas. Nos locais onde era descontínua, passou gradualmente a sobressairse na paisagem à medida que o material mais fino ia sendo removido de seu contorno, caracterizando uma inversão do relevo e originando os morros residuais. Essas bancadas lateríticas constituíram, também, obstáculo ao livre movimento da água infiltrada na chapada, fazendo com que o tempo de residência de água nos solos mais próximos das bordas se tornasse mais extenso, estabelecendo-se um gradiente de regime hídrico entre o centro (ligeiramente mais elevado) e as bordas do planalto, o que induziu à distribuição de solos hoje observada nas chapadas mais amplas da região.

Com a instalação de novo período úmido, teve início outra fase de intemperismo, acentuando o aprofundamento das linhas de drenagem. Grande parte do material da segunda superfície foi removido, e as rochas subjacentes começaram a ser retrabalhadas. Abriram-se, então, os vales da terceira superfície, que ainda hoje progridem com o dissecamento das mais antigas. A morfologia regional derivou, assim, para uma feição aproximada da atual (Figura $2 \mathrm{~V}$ ).

\section{Conclusões}

1. A grande homogeneidade granulométrica dos solos da superfície geomórfica mais elevada (chapadas), com perfis invariavelmente muito argilosos, indica independência do substrato rochoso com a distribuição condicionada à variação do regime hídrico ao longo da toposseqüência.

2. Sob a segunda superfície geomórfica, as características dos solos indicam a contribuição de sedimentos da cobertura terciária em mistura com o material proveniente da decomposição das rochas subjacentes.

3. Os solos das áreas de dissecação mais recente, correspondentes à terceira superfície geomórfica, apresentam características fortemente influenciadas pelo substrato geológico. 


\section{Agradecimentos}

Aos professores Nilton Curi e Mauro Resende, respectivamente, da Universidade Federal de Lavras e Universidade Federal de Viçosa, pelas sugestões apresentadas.

\section{Referências}

BRASIL. Ministério de Minas e Energia. Departamento Nacional de Produção Mineral. Carta geológica do Brasil ao milionésimo: folha Goiânia (SE-22). Brasília, 1975. $87 \mathrm{p}$.

BRASIL. Ministério de Minas e Energia. Departamento Nacional da Produção Mineral. Projeto RADAMBRASIL. Folha SE 22 Goiânia: geologia, geomorfologia, pedologia, vegetação e uso potencial da terra. Rio de Janeiro, 1983. 768 p. (Levantamento de Recursos Naturais, 31).

BRAUN, O. P. G. Contribuição à geomorfologia do Brasil Central. Revista Brasileira de Geografia, Rio de Janeiro, v. 32, n. 3, p. 3-39, 1971.

CARMO, D. N.; CURI, N.; RESENDE, M. Caracterização de latossolos da região do Alto Paranaíba (MG). Revista Brasileira de Ciência do Solo, v. 8, p. 235-240, 1984.

CAVALCANTE, A. C. Estudo de latossolos argilosos do planalto central do Brasil. 1977. 185 f. Dissertação (Mestrado) - Universidade Federal Rural do Rio de Janeiro, Rio de Janeiro.

CLINE, M. G.; BUOL, S. W. Solos do planalto central do Brasil. Ithaca: Cornell University, 1973. 27 p.

CORRÊA, G. F. Les microreliefs "murundus" et leur environnement pédologique dans l'ouest de Minas Gerais, région du plateau central brésilien. 1989. $144 \mathrm{f}$. Thèse (Doctorat) - Université de Nancy I, Vandoeuvre Lès Nancy.

DANIELS, R. B.; GAMBLE, E. E.; CADY, J. G. The relation between geomorphology and soil morphology and genesis. Advances in Agronomy, San Diego, n. 23, p. 5188, 1971.

EMBRAPA. Centro Nacional de Pesquisa de Solos (Rio de Janeiro, RJ). Sistema brasileiro de classificação de solos. Brasília: Embrapa-SPI, 1999. 412 p.

EMBRAPA. Serviço Nacional de Levantamento e Conservação de Solos (Rio de Janeiro, RJ). Levantamento de reconhecimento de alta intensidade dos solos e aptidão agrícola das terras dos municípios de Silvânia e São Miguel do Passa Quatro, GO. Rio de Janeiro, 1992. $331 \mathrm{p}$.
EMBRAPA. Serviço Nacional de Levantamento e Conservação de Solos (Rio de Janeiro, RJ). Levantamento de reconhecimento de baixa intensidade dos solos e aptidão agrícola das terras de parte da região geoeconômica de Brasília. Rio de Janeiro, 1983. 515 p. (Boletim de Pesquisa, 24).

EMBRAPA. Serviço Nacional de Levantamento e Conservação de Solos (Rio de Janeiro, RJ). Levantamento de reconhecimento dos solos e aptidão agrícola das terras do Triângulo Mineiro. Rio de Janeiro, 1982. 526 p. (Boletim de Pesquisa, 1).

EMBRAPA. Serviço Nacional de Levantamento e Conservação de Solos (Rio de Janeiro, RJ). Manual de métodos de análise de solos. Rio de Janeiro, 1979. Não paginado.

FEUER, R. An exploratory investigation of the soils and agricultural potential of the soils of the future Federal District in the central plateau of Brazil. 1956. 432 p. Thesis (Ph.D) - Cornell University, Ithaca.

KER, J. C.; RESENDE, M. Recursos edáficos dos cerrados: ocorrência e potencial. In: SIMPÓSIO SOBRE O CERRADO, 8.; INTERNATIONAL SYMPOSIUM ON TROPICAL SAVANNAS, 1.,1996, Brasília. Anais... Planaltina: Embrapa-CPAC, 1996. p. 15-19.

KING, L. C. A geomorfologia do Brasil Oriental. Revista Brasileira de Geografia, Rio de Janeiro, v. 18, n. 2, p. 147265, 1956.

LEMOS, R. C.; SANTOS, R. D. Manual de descrição e coleta de solo no campo. 2. ed. Campinas: Sociedade Brasileira de Ciência do Solo/Embrapa-CNPS, 1996. 84 p.

LEPSCH, I. F.; BUOL, S. W. Oxisol-landscape relationships in Brazil. In: INTERNATIONAL SOIL CLASSIFICATION WORKSHOP, 8., 1986, Rio de Janeiro. Proceedings... Rio de Janeiro: Embrapa-SNLCS/ USDA/UFPR, 1988. part 1, p. 174-189.

MACEDO, J.; BRYANT, R. B. Morphology, mineralogy and genesis of a hydrosequence of oxisols in Brazil. Soil Science Society of America Journal, Madison, v. 51, p. 690-698, 1987.

MOTHCI, E. P. Características e gênese de uma seqüência de oxisols no planalto central brasileiro. 1977. 107 f. Dissertação (Mestrado) - Universidade Federal do Rio Grande do Sul, Porto Alegre.

MOTTA, P. E. F. da; KÄMPF, N. Iron oxide properties as support to soil morphological features for prediction of moisture regimes in Oxisols of Central Brazil. Zeitschrift fuer Pflanzenernaehrung und Bodenkunde, Weinheim, n. 155 , p. 385-390, 1992. 
QUEIROZ NETO, J. P. Solos da região dos cerrados e suas interpretações. Revista Brasileira de Ciência do Solo, Campinas, v. 6, n. 1, p. 1-12, 1982.

RESENDE, M.; CURI, N.; REZENDE, S. B.; CORRÊA, G. F. Pedologia: base para distinção de ambientes. Viçosa, MG: Núcleo de Estudo de Planejamento e Uso da Terra, 1999. $367 \mathrm{p}$.

RESENDE, M.; SANTANA, D. P.; CURI, N. Pedologia e fertilidade do solo: interações e aplicações. Lavras: Esal, 1988. $81 \mathrm{p}$.

REUNIÃO TÉCNICA DE LEVANTAMENTO DE SOLOS, 10., 1979, Rio de Janeiro. Súmula... Rio de Janeiro: Embrapa-SNLCS, 1979. 85 p. (Miscelânea, 1).

RODRIGUES, T. E.; KLAMT, E. Mineralogia e gênese de uma seqüência de solos do Distrito Federal. Revista Brasileira de Ciência do Solo, Campinas, v. 2, n. 2, p. 132-139, 1978.
RUHE, R. Quaternary landscapes in Iowa. Ames: Iowa State University Press, 1969. 255 p.

SCHWERTMANN, U. Occurrence and formation of iron oxides in various pedoenvironments. In: STUCKY, J. W.; GOODMAN, B. A.; SCHWERTMANN, U. (Ed.). Iron in soils and clay minerals. Dordrecht: D. Reidel, 1988. p. 267-302. (NATO ASI Serie C: Mathematical and Physical Sciences, 217).

SUGUIO, K.; BIGARELlA, J. J. Ambiente fluvial. Curitiba: UFPR, 1979. 183 p. (Ambientes de Sedimentação e sua Interpretação e Importância).

VALENTE, C. R.; VENEZIANI, P. Mapeamento geológico em áreas de espessa cobertura de Latossolo. In: SIMPÓSIO BRASILEIRO DE SENSORIAMENTO REMOTO, 5., 1988, São José dos Campos. Anais... Natal: Instituto Nacional de Pesquisas Espaciais/Sociedad de Especialistas Latinoamericanos en Percepción Remota, 1988. v. 2, p. 381-389. 